\title{
MATCH ANALYSIS IN RINK HOCKEY: A SYSTEMATIC REVIEW
}

review paper

(c) Wroclaw University of Health and Sport Sciences

DOI: https://doi.org/10.5114/hm.2022.111227

\section{TIAGO SOUSA $^{1 \oplus}$, HUGO SARMENTO $^{1 \oplus}$, LIAM D. HARPER $^{2}$, JOÃO VALENTE-DOS-SANTOS ${ }^{1,3}$, VASCO VAZ ${ }^{1 \oplus}$}

${ }^{1}$ University of Coimbra, Research Unit for Sport and Physical Activity (CIDAF), Faculty of Sport Sciences and Physical Education, Coimbra, Portugal

${ }^{2}$ Division of Sport and Exercise Sciences, University of Huddersfield, Huddersfield, United Kingdom

${ }^{3}$ CIDEFES, Centro de Investigação em Desporto, Educação Física e Exercício e Saúde, Universidade Lusófona, Lisboa, Portugal

\begin{abstract}
The purpose of this paper was to review the available literature on match analysis in rink hockey. To be included in this review, the publications should have been written in English or Portuguese, have contained relevant data about match analysis in rink hockey, and have been published as original papers, reviews, book chapters, or academic works. A systematic review of Web of Science, SPORTDiscus, PubMed, Scopus, b-on, and Open Access Scientific Portuguese Repository (RCAAP) was performed in accordance with the Preferred Reporting Items for Systematic Reviews and Meta-Analyses guidelines on July 24, 2020. A risk-of-bias quality form was adapted to evaluate the publications. To make a fair comparison between studies of different designs, a percentage score was calculated as a final measure of methodological quality. From the 20 selected studies, 8 were classified as having excellent methodological quality and 12 had good methodological quality. To organize the results, the material was categorized in 2 analysis levels: (i) dependent on the type of analysis performed; (ii) based on the type of variables analysed. This review highlights that rink hockey could be characterized as a sport where half of the offensive actions end with a shot at goal, but only a small number of these shots end with a goal. Furthermore, there are differences in technical demands between player positions and reductions in movement intensity in the second halves of matches. Future research should provide more scientific knowledge on the sport, using new technologies and new approaches to study tactical sequential events.
\end{abstract}

Key words: roller hockey, hardball hockey, game analysis, performance analysis, team sports

\section{Introduction}

Increased utilization of technology and application of empirical data can enhance the development of a sport and improve athletic performance [1]. There is a broad range of resources and methods used by coaches and researchers to increase their knowledge and improve the quality of players and teams [2]. To provide better understanding of the constraints that can negatively impact on sporting success, match analysis has assumed a significant role [2, 3].

It was in the English county of Kent in 1926 that the first European men's hockey skating championship was carried out, with the first World Championship held in 1936 in the city of Stuttgart [4]. In 1992 at the Olympic Games in Barcelona, it was presented as a demonstration sport. However, it was not accepted as an official sport. Despite this setback, the sport did not stop expanding and today is played in 30 countries over 5 continents. As of 2014, there were 833 registered clubs and 4626 teams playing rink hockey [5].

Much of the knowledge of rink hockey is adapted from other sports, which have distinct differences. This lack of systematic and consistent theoretical and practical background makes it harder to provide useful information for coaches [1]. The scientific research

Correspondence address: Tiago Sousa, Faculty of Sport Sciences and Physical Education, University of Coimbra, Avenida Conímbriga, Pavilhão 3, 3040-248 Coimbra, Portugal, e-mail: tiagosousa77@gmail.com2, https://orcid.org/0000-00020024-8861

Received: March 31, 2021

Accepted for publication: November 23, 2021

Citation: Sousa T, Sarmento H, Harper LD, Valente-dos-Santos J, Vaz V. Match analysis in rink hockey: a systematic review. Hum Mov. 2022;23(3):33-48; doi: https://doi.org/10.5114/hm.2022.111227. 


\section{HUMAN MOVEMENT}

T. Sousa et al., Match analysis in rink hockey

carried out in rink hockey is minimal and, to the best of our knowledge, only 2 studies have been performed to summarize and review the available rink hockey literature [6, 7]. Kingman and Dyson [6] concluded 19 years ago that much of the published literature was historical reviews of the sport or specific studies devoted to the characterization of physiological demands of training and competition. Since this review, some crucial studies have been carried out on topics such as: (1) morphological and physiological demands [8]; (2) talent identification [9]; and (3) dietary intake and body composition [10]. More recently, Ferraz et al. [7] made a review of the evolutionary tendencies of research regarding male rink hockey players' and game performance, focusing on (1) physiological demands; (2) anthropometry and body composition; (3) game characterization/patterns; and (4) injuries.

Although there is an increase in the number of research papers devoted to this specific sport, there is no published review of the available literature on rink hockey match analysis, despite similar reviews available in sports such as football [11], futsal [12], handball [13], volleyball [14], and basketball [14]. A systematic review of the available literature on rink hockey match analysis may help coaches and practitioners to better understand the most common research topics and the demands of the sport. Therefore, the purpose of this study was to systematically review and organize the literature devoted to match analysis in rink hockey.

\section{Material and methods}

The study was designed in accordance with the 2009 guidelines of the Preferred Reporting Items for Systematic Reviews and Meta-Analyses (PRISMA).

\section{Eligibility criteria}

The eligibility criteria for the selection of the scientific publications for this systematic review were: (1) must be written in English or Portuguese; (2) contain relevant data about match analysis in rink hockey; (3) be published as an original paper, review, book chapter, or academic work (such as a doctoral thesis, master thesis, etc.). All the publications that did not meet the inclusion criteria were excluded from this review.

Information sources, search strategy,

and data collection process

The review of the available literature was conducted in accordance with the PRISMA guidelines. Two inde- pendent reviewers (TS and VV) separately performed the analysis on July 24, 2020. The electronic databases of Web of Science, SPORTDiscus, PubMed, Scopus, b-on, and Open Access Scientific Portuguese Repository (RCAAP, Repositórios Científicos de Acesso Aberto de Portugal) were researched for relevant publications by using the key keywords "Roller Hockey" and "Rink Hockey", each associated with the terms "Match analysis", "Performance analysis", and "Game analysis". If there was disagreement amongst the authors regarding the inclusion of specific articles, the final decision was left to the senior author (JVS). The studies were assembled in accordance with the primary research topics of match analysis and the methodological strategies used.

\section{Study risk of bias assessment}

To evaluate the quality of the studies, a risk-of-bias quality form was adapted from Sarmento et al. [11, 15] to assess qualitative and quantitative publications.

Quantitative studies were assessed on the basis of 16 items: purpose (item 1), relevance of background literature (item 2), appropriateness of study design (item 3), sample studied (items 4 and 5), use of informed consent procedure (item 6), outcome measures (items 7 and 8), method description (item 9), significance of results (item 10), analysis (item 11), practical importance (item 12), description of drop-outs (item 13), conclusions (item 14), practical implications (item 15), and limitations (item 16). All the 16 quality criteria were scored on a binary scale (0/1); 2 of those criteria (items 6 and 13) presented the option: 'If not applicable, assume NA'. Qualitative studies were assessed on the basis of 21 critical components: objective (item 1), literature review (item 2), study design (items 3, 4, and 5), sampling (items 6, 7, 8, and 9), data collection (descriptive clarity: items 10,11 , and 12 ; procedural rigor: item 13), data analysis (analytical rigor: items 14 and 15; auditability: items 16 and 17; theoretical connections: item 18), overall rigor (item 19), and conclusion/implications (items 20 and 21).

As in previous research $[11,16]$, and to make a fair comparison between studies of different designs, the decision was taken to calculate a percentage score as a final measure of methodological quality. This final score is the result of the sum of every score in a given study divided by the total number of items for that specific research design (i.e., 16 or 21). Articles were classified as: (1) low methodological quality - with a score $\leq 50 \%$; (2) good methodological quality $-51-75 \%$; 
and (3) excellent methodological quality - with a score $>75 \%$ [16]. One author (TS) extracted the data, and another (JVS) verified them, with disagreements resolved in discussions between these 2 authors.

\section{Results}

Search, selection, and inclusion of publications

The research performed in the databases and other sources allowed us to identify 1789 publications. These data were then exported to reference manager software (EndNote X8), and any duplicates (932 references) were eliminated automatically. For the remaining publications (857), the title and abstract were then screened for relevance, resulting in another 799 studies being removed from the database. The full texts of the remaining 58 publications were read, and another 38 were rejected owing to a lack of relevance to the purpose of this review (Figure 1). The reason for exclusion was that the publication did not concern match analysis (33 publications excluded) or it was not written in English or Portuguese (5 publications excluded).

At the end of the screening procedure, 20 publications (10 original papers, 1 doctoral thesis, 2 master theses, and 7 graduate theses) received further in-depth reading and analysis for the systematic review. From these 20 publications, 9 were written in Portuguese and 11 in English.

In order to organize the results of this review, we categorized the material as a function of 2 levels of analysis, as suggested by Sarmento et al. [15]: a firstorder level, dependent on the type of analysis performed (descriptive analysis and comparative analysis); and a second-order level, based on the type of variables analysed (Figure 2). The aim was not to produce cate-

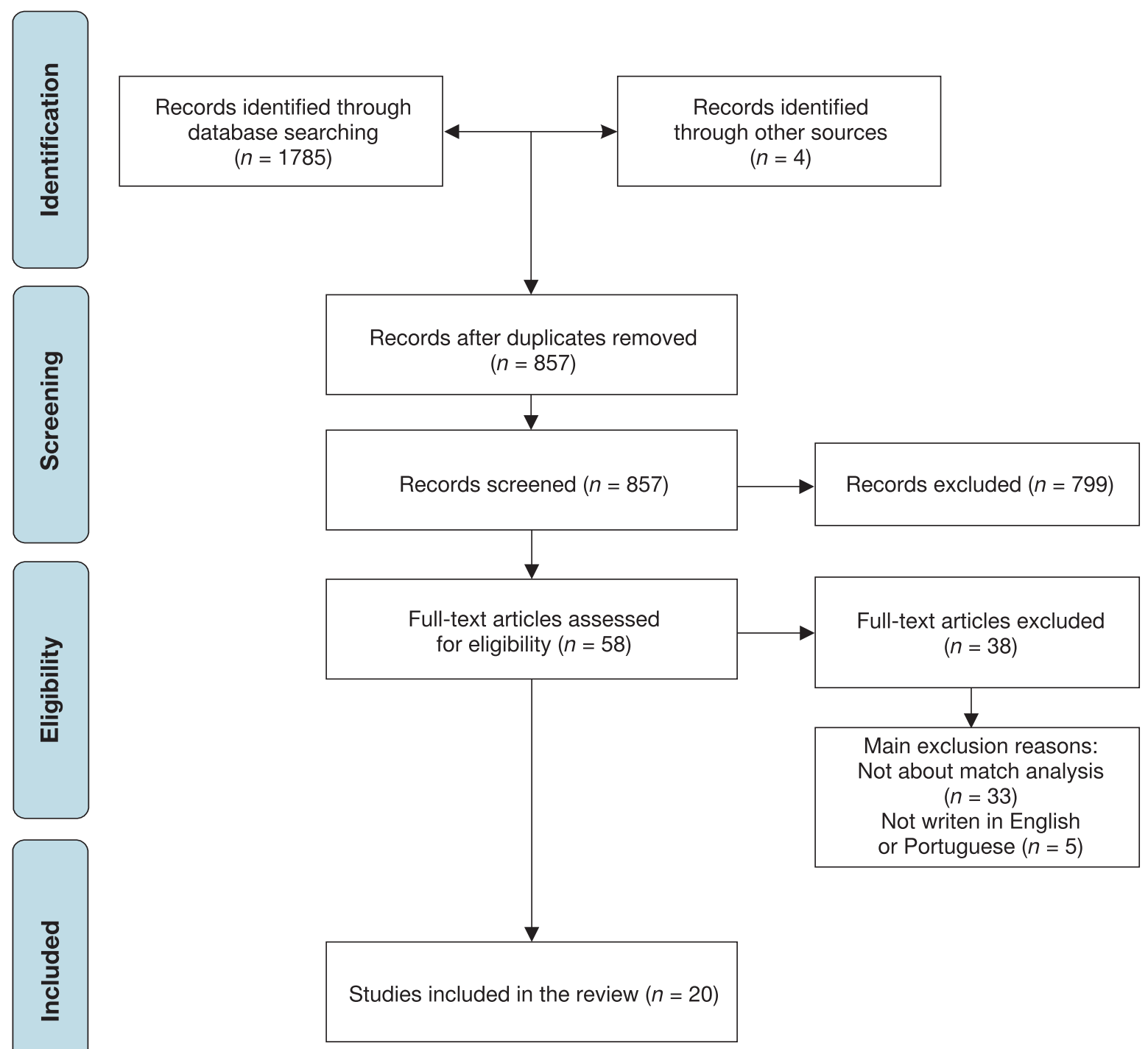

Figure 1. Flowchart of methodology used for search 


\section{HUMAN MOVEMENT}

T. Sousa et al., Match analysis in rink hockey

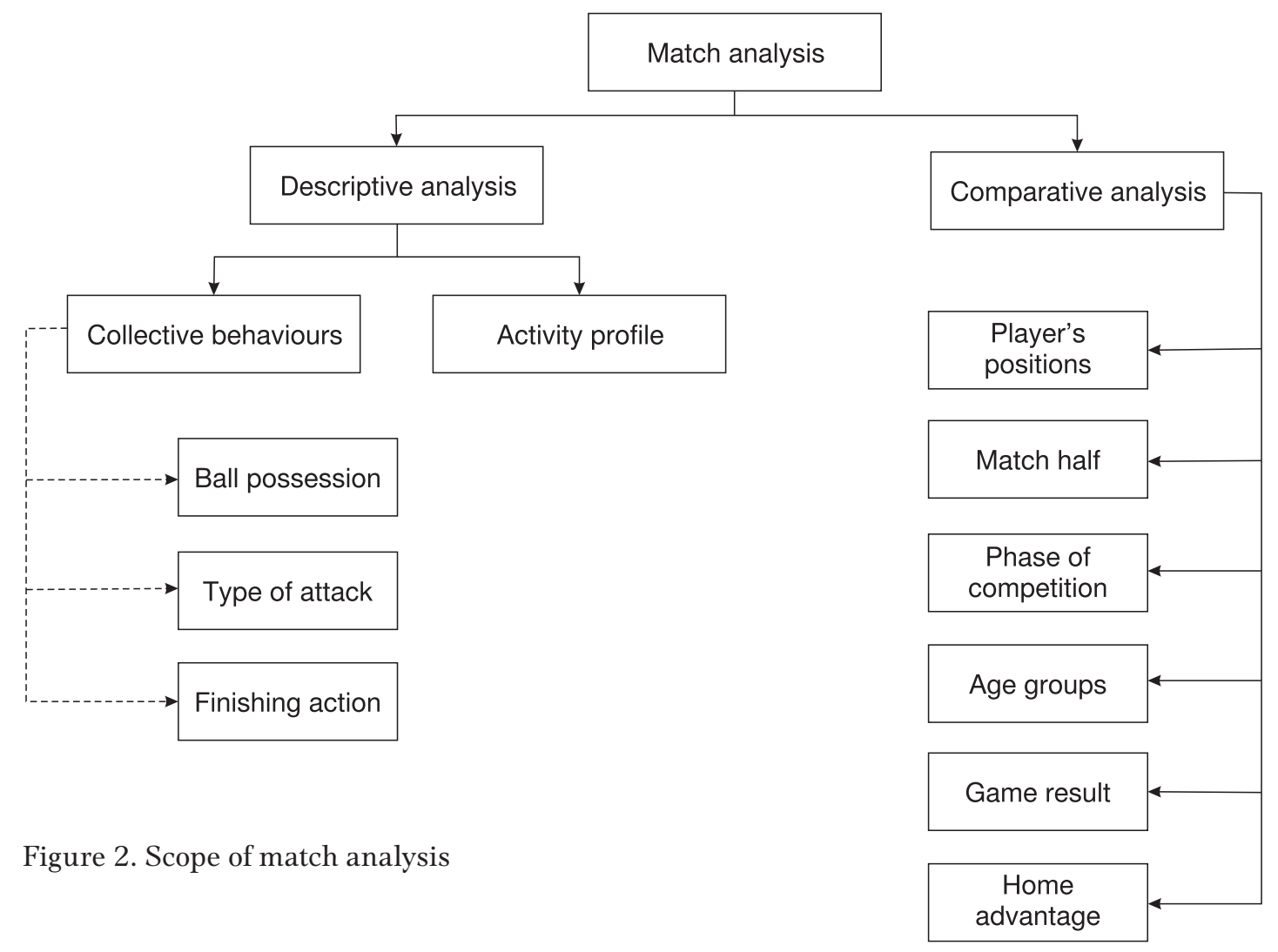

gories that were mutually exclusive as the same analyses can include topics that relate to different categories. Thus, a study included in a specific 'category' could also be classified in another 'category' if the content justified its inclusion.

\section{Quality of the studies}

The quality of indicators for the studies included in this review were as follows: (1) the average methodological quality score for the 20 selected studies was 69.1\%; (2) none of the studies achieved 100\%; (3) none of the studies scored below 50\%; (4) 5 studies scored higher than $75 \%$ (excellent methodological quality); (5) 15 studies scored equal or lower than $75 \%$ and equal or higher than $51 \%$ and (good methodological quality).

Some of the limitations identified in the reviewed studies were as follows: (1) some studies did not report an explicit justification of the sample size; (2) most of the studies did not indicate that informed consent was obtained from each participant.

General limitations of the reviewed studies

Here are some limitations of the reviewed studies: (1) almost half of them (9 studies) were written in Por- tuguese, which limits the international dissemination of information; (2) only half of the 20 studies reviewed were published in international journals; (3) most of the studies $(60 \%)$ were published prior to 2009 ; in 2009 , profound changes were introduced to the rules of the game, which may limit the applicability of data published earlier; (4) rink hockey has a low number of publications related to match analysis; (5) only 2 of the studies analysed the use of recent technology (e.g., global positioning systems) and the activity profile of players.

\section{Major research topics}

After in-depth analysis, it was decided to categorize the results into descriptive analysis and comparative analysis. Within the descriptive analysis, the results were presented in 2 major categories: (1) collective behaviours and (2) activity profile. The category 'collective behaviours' was presented in 3 topics: (1) ball possession; (2) type of attack; and (3) finishing action. Within the comparative analysis, the results were presented by using 6 topics: (1) player position; (2) match half; (3) phase of competition; (4) age groups; (5) game result; and (6) home advantage. 


\section{Descriptive analysis}

The common aim of the reviewed studies was to characterize the game of rink hockey through the description of collective behaviours or activity profile (Table 1). However, there are some exceptions [17-19], where authors compared winning teams with losing teams in addition to the descriptive analysis.

Within descriptive approaches, most of the researchers sought to study age-related differences in under-17
(U-17) [18-20], under-20 (U-20), and senior players $[17,21-25]$. In these studies, the authors focused their attention mainly on: (1) ball possession [17-22, 26, 27]; (2) type of attack [17-22, 26, 28]; (3) finishing actions $[17,18,20,23,29]$; and (4) activity profile [23-25, 30-33] (Table 1).

To better understand where interactions are performed by rink hockey players, Vaz et al. [28] delineated the rink hockey field into 18 zones (Figure 3).

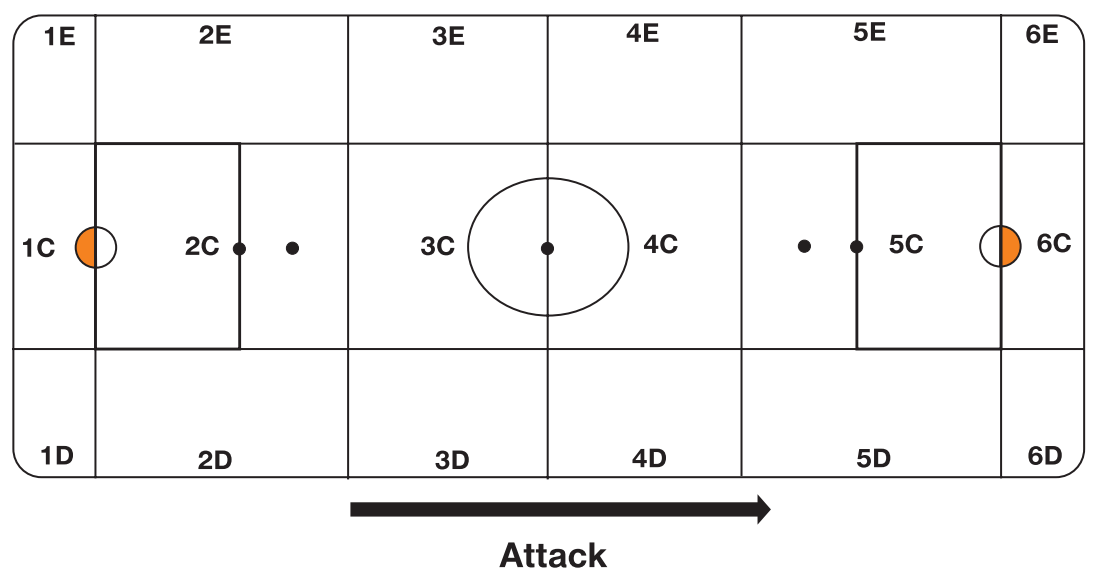

Figure 3. The rink hockey field divided into 18 areas in 3 corridors ( $\mathrm{E}$ - left, $\mathrm{C}$ - central, $\mathrm{D}$ - right) [28]

Table 1 . Studies with predominantly descriptive analysis

\begin{tabular}{|c|c|c|c|c|}
\hline Study & Sample & Variables & Main results & $\begin{array}{c}\text { Quality } \\
\text { score (\%) }\end{array}$ \\
\hline $\begin{array}{l}\text { Kingman } \\
\text { and Dyson } \\
{[33]}\end{array}$ & $\begin{array}{l}\text { - England national } \\
\text { team and } 5 \text { national } \\
\text { Premier League teams } \\
\text { - } 6 \text { matches }\end{array}$ & - Activity profile & $\begin{array}{l}\text { The most considerable number of goals were scored in } \\
\text { the top right of the goal. Usually, goalkeepers are thought } \\
\text { to be weaker on the top left of the goal because of the use } \\
\text { of the stick. Goalkeepers are thought to be less mobile } \\
\text { on the side of the hand that holds the stick }\end{array}$ & 56.3 \\
\hline $\begin{array}{l}\text { Mendo and } \\
\text { Anguera } \\
\text { Argilaga } \\
{[27]}\end{array}$ & $\begin{array}{l}-6 \text { premier division } \\
\text { matches involving } \\
6 \text { different teams } \\
-66 \text { professional } \\
\text { players from the } \\
\text { Spanish premier } \\
\text { division }\end{array}$ & - Ball possession & $\begin{array}{l}\text { The description and interpretation of patterns of play } \\
\text { also have implications for psychosocial intervention. } \\
\text { The study of the patterns shed light on the behavioural } \\
\text { development of real play; the patterns determine both } \\
\text { the intervention at each link in the behaviour chain and } \\
\text { the consideration of intervention techniques or strategies } \\
\text { suited to improving players' resources }\end{array}$ & 68.8 \\
\hline Ferreira [17] & $\begin{array}{l}-5 \text { teams from } \\
\text { the elite Portuguese } \\
\text { Premier League } \\
-4 \text { matches from } \\
\text { seasons } 2000 / 2001 \text {, } \\
2001 / 2002 \text {, and } \\
2002 / 2003\end{array}$ & $\begin{array}{l}\text { - Ball possessions } \\
\text { - Type of attack } \\
\text { - Finishing action } \\
\text { - Game result }\end{array}$ & $\begin{array}{l}\text { The actions that create ball possession are tackles, } \\
\text { missed shots, and shots at goal not scored. Most ball } \\
\text { possessions begin in defensive areas. Counter-attacks } \\
\text { and fast attacks begin after a mistake from the opponent, } \\
\text { while the organized attack normally begins after a shot. } \\
\text { Fast attacks are the phases of the game that result in more } \\
\text { shots attempted, with a higher degree of effectiveness. } \\
\text { Counter-attacks, taking into account that there is a numer- } \\
\text { ical superiority of the attack, have a lower percentage } \\
\text { of attempted shots presenting the same efficacy index } \\
\text { than the organized attack. There are no differences } \\
\text { between winners and losers when ball possession is } \\
\text { considered. Winners tend to perform more counter- } \\
\text { attacks and organized attacks }\end{array}$ & 62.5 \\
\hline
\end{tabular}




\section{HUMAN MOVEMENT}

T. Sousa et al., Match analysis in rink hockey

\begin{tabular}{lll}
\hline Duque [18] & - European & - Ball possessions \\
& championship U-17 & - Type of attack \\
& -5 national teams & - Game result \\
& -4 matches analysed &
\end{tabular}

The most frequent ways of regaining ball possession are faults and defensive recovery. In every phase of the game, ball possession starts in defensive areas and the intermediate area of the field. Counter-attack begins $87 \%$ of the time after a mistake from the opponent, while fast attacks and organized attacks tend to be initiated after a fault, offensive rebound, or goal. Counter-attacking is the phase of the game that has most shots attempted, whilst also presenting a higher effectiveness index. Organized attacks are the phases of the game were the effectiveness index is lowest. Winning teams have more ball possession than losing teams

$\begin{array}{lll}\text { Ferreira [21] } & \text { - European } & \text { - Ball possessions } \\ & \text { championship U-20 } & \text { - Type of attack } \\ & -4 \text { matches } & \end{array}$

The most common way of regaining ball possession is through faults and defensive recovery. Counter-attack, fast attack, and organized attack originate in defensive areas. The action of ball recovery that most commonly precedes a counter-attack is tackle, while the origin of fast attacks is typically defensive recovery. An intercepted pass is the most critical action that precedes an organized attack. In situations of counter-attack, the end of ball possession is mainly by attempted shots, and the end of ball possession occurs mostly in the offensive central area and owing to tackles. In situations of an organized attack, the end of ball possession is usually owing to faults

$\begin{array}{lll}\text { Clérigo [22] } & - \text { U-20 Portuguese } & \text { - Ball possessions } \\ & \text { rink hockey teams } & \text { - Type of attack } \\ & -4 \text { matches } & \end{array}$

The actions that cause regain of ball possession are defensive recovery, faults, and tackles. The main areas to begin ball possession are the defensive areas. Tackles play an important role in the beginning of a counter-attack, whilst defensive recovery is the most crucial action before a fast attack. 35\% of organized attacks are initiated after a fault. Shots at goal are the most frequent offensive action associated with the end of ball possession during counter-attacks and fast attacks. In situations of organized attacks, faults are the action most commonly associated with the end of ball possession, followed by shots

\begin{tabular}{lll}
\hline Rosa [19] & - Final 4 U-17, & - Ball possessions \\
& $2005 / 2006$ & - Type of attack \\
& -4 teams & - Game result \\
& -4 matches &
\end{tabular}

The actions that lead to the beginning of ball possession are defensive actions of defensive recovery, followed by faults and then offensive recovery. Teams start ball possession in the defensive area. Tackles are the most critical actions during the beginning of counter-attacks and fast attacks, while organized attacks develop after faults and shots at goal. Winning teams have more ball possession in organized attack, and losing teams prefer fast attacks and counter-attacks. However, in the second half of matches, winning teams prefer fast attacks and counter-attacks, while losing teams have more ball possession

Ferreira [34] - 10 games from first Portuguese league in 2007/2008 between teams that had qualified for the play-offs
Offensive decisional behaviour influences the efficiency

- Finishing action of finalization actions, with linear actions developing into ball control and non-linear actions developing into shooting actions. Defensive decisional behaviour influences the efficiency of finalization actions, with a defensive response behind the goal developing into relative efficiency with ball control, and a defensive response in front of the goal developing into a shot 


\begin{tabular}{|c|c|c|c|c|}
\hline Vaz [20] & $\begin{array}{l}\text { - U-17 Portuguese } \\
\text { national team } \\
\text { - International } \\
\text { competition }\end{array}$ & $\begin{array}{l}\text { - Ball possessions } \\
\text { and type of } \\
\text { possession } \\
\text { - Type of attack } \\
\text { - Finishing action } \\
\text { - Age groups }\end{array}$ & $\begin{array}{l}\text { Characterization of game systems of the Portuguese } \\
\text { U-17 national team }\end{array}$ & 93.8 \\
\hline Sousa [29] & $\begin{array}{l}\text { - Rink hockey } \\
\text { managers }\end{array}$ & - Finishing action & $\begin{array}{l}\text { This study sought to examine which parameters are } \\
\text { considered most relevant in observation and analysis } \\
\text { of the performance of the teams and } \\
\text { athletes by rink hockey managers }\end{array}$ & 80.9 \\
\hline $\begin{array}{l}\text { Vaz et al. } \\
{[28]}\end{array}$ & $\begin{array}{l}\text { - } 8 \text { rink hockey } \\
\text { players aged } 14.5-16.5 \\
\text { from the Portuguese } \\
\text { national team } \\
\text { that participated } \\
\text { in the } 2007 \text { and } \\
2008 \text { editions of } \\
\text { the U-17 European } \\
\text { championship }\end{array}$ & - Type of attack & $\begin{array}{l}\text { The results permitted the identification of the centroid } \\
\text { player and his role in team activity and concluded that } \\
\text { rink hockey could be described as an open system able } \\
\text { to create clusters of connectivity between players }\end{array}$ & 75 \\
\hline
\end{tabular}

$\begin{array}{llll}\begin{array}{l}\text { Sousa et al. } \\ \text { [23] }\end{array} & \begin{array}{l}\text { - } 1713 \text { shots at goal } \\ \text { from the 2016/2017 } \\ \text { season in the }\end{array} & \begin{array}{l}\text { - Context of } \\ \text { attacking play } \\ \text { Portuguese Rink } \\ \text { Hockey First Division }\end{array} & \begin{array}{l}\text { Goalkeepers are more effective in the first half vs. the } \\ \text { attacking play } \\ \text { second half of the matches. Goalkeeping performance } \\ \text { was also lower in the direct free hits and penalties when } \\ \text { attacking play }\end{array} \\ & \begin{array}{l}\text { compared with indirect free hits. The technique most } \\ \text { used by the rink hockey goalkeepers to save shots at goal } \\ \text { is the 'knee on the floor'. Observations demonstrate that } \\ \text { when the attack begins in the opposition defensive area, } \\ \end{array} & \begin{array}{l}\text { teams are 55\% more likely to score. The shots at the upper } \\ \text { zones of the goal have a higher probability of being suc- } \\ \text { cessful }\end{array}\end{array}$

Fernández et - 8 professional rink - Distance travelled Regarding external load competitive demands, the disal. [25] hockey players in meters tance travelled data from this study place rink hockey - Distance covered behind outdoor sports. The distance travelled by minute above $18 \mathrm{~km} / \mathrm{h} \quad$ for the players analysed is higher than that for players from in meters - Player load, vector magnitude other indoor sports. There are no differences between - Number of interior and exterior players in terms of external load high-intensity accelerations - Number of high-intensity decelerations

Fernández et $\quad-8$ professional rink al. [24] hockey players
- Distance covered in high-speed skating
Training drills could not reproduce the maximum conditional effort that occurs in an official match in any time window. Moreover, all the situations and games analysed had higher levels of effort as the time of the window studied decreased 


\section{HUMAN MOVEMENT}

T. Sousa et al., Match analysis in rink hockey

Table 2. Studies with predominantly comparative analysis

\begin{tabular}{|c|c|c|c|c|}
\hline Study & Sample & Variables & Main results & $\begin{array}{c}\text { Quality } \\
\text { score (\%) }\end{array}$ \\
\hline
\end{tabular}

\begin{tabular}{lll}
\hline Kingman & -2 Premier English & - Players' position \\
and Dyson & rink hockey matches & \\
[31] & -16 subjects & \\
& (4 in each team & \\
& at the time, excluding \\
& the goalkeeper)
\end{tabular}

\begin{tabular}{|c|c|c|c|}
\hline $\begin{array}{l}\text { Kingman } \\
\text { and Dyson } \\
{[32]}\end{array}$ & $\begin{array}{l}\text { - } 2 \text { Premier English } \\
\text { rink hockey matches } \\
-16 \text { subjects } \\
\text { ( } 4 \text { in each team } \\
\text { at the time, excluding } \\
\text { the goalkeeper) }\end{array}$ & $\begin{array}{l}\text { - Players' position } \\
\text { - Match half } \\
\text { - Game result }\end{array}$ & $\begin{array}{l}\text { There is a minor position effect for the type of action } \\
\text { performed, but no position effect for the intensity } \\
\text { and direction of movement in a rink hockey match, } \\
\text { supporting the argument that there are no differenc } \\
\text { es between players' positions }\end{array}$ \\
\hline Bastos [30] & $\begin{array}{l}\text { - } 6 \text { games of the } \\
\text { Portuguese national } \\
\text { team during the } 2003 \\
\text { World Cup } \\
\text { - } 1 \text { vs. } 1 \text { actions }\end{array}$ & $\begin{array}{l}\text { - Phase of } \\
\text { competition }\end{array}$ & $\begin{array}{l}\text { The numbers of goals scored in situations of } 1 \text { vs. } 1 \\
\text { are higher in the group phase in comparison with } \\
\text { the knockout phase. The type of dribble more often } \\
\text { used is the dribble in progression. After } 1 \text { vs. } 1 \text {, } \\
\text { teams often keep possession of the ball. The offen- } \\
\text { sive area is where players mostly perform } 1 \text { vs. } 1 \text { 's, } \\
\text { preferentially in the central corridor }\end{array}$ \\
\hline
\end{tabular}

Rink hockey is a fast and dynamic sport because of a significant amount of high-intensity activities and a large number of actions performed in quick succession performed, but no position effect for the intensity supporting the argument that there are no differenc-
es between players' positions

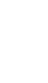

are higher in the group phase in comparison with

the knockout phase. The type of dribble more often teams often keep possession of the ball. The offensive area is where players mostly perform 1 vs. 1's, Organized attack is the primary phase of rink hockey.

\begin{tabular}{llll}
\hline Valente-dos- & -8 matches from the & - Ball possession & Organized attack is the primary phase of rink hockey. \\
Santos [26] & 2005 World Cup & - Type of attack & The central defensive area is where the majority of \\
- Data from Duque & - Age groups & ball possessions begin. The senior game is charac- \\
[18] & & terized by a low efficiency but compared with U-17 \\
- Data from Ferreira & & \\
[21] & &
\end{tabular}

\begin{tabular}{|c|c|c|}
\hline $\begin{array}{l}\text { Oliveira } \\
\text { et al. [35] }\end{array}$ & $\begin{array}{l}\text { - } 54 \text { rink hockey }- \text { Age groups } \\
\text { players } \\
-5 \text { different levels } \\
\text { (10 players from U-12, } \\
11 \text { from U-14, } 10 \text { from } \\
\text { U-16, } 12 \text { from U-18, } \\
\text { and } 11 \text { elite players } \\
\text { aged over } 20 \text { years) } \\
-3 \text { official matches }\end{array}$ & $\begin{array}{l}\text { The results demonstrated no statistically significant } \\
\text { differences in centrality levels between different age } \\
\text { groups. Nevertheless, differences were found between } \\
\text { tactical positions in both centrality metrics computed } \\
\text { in this study }\end{array}$ \\
\hline
\end{tabular}

- Home advantage The home advantage was higher than 50\% in both leagues, with significantly higher values in the male league. Teams scored a higher percentage of goals when playing at home, no differences were found between genders. Regarding the number of goals scored per match, the results showed differences between genders, with higher values in the men's league

$\begin{array}{lll}\begin{array}{l}\text { Arboix-Alió } \\ \text { et al. [36] }\end{array} & \begin{array}{l}\text { (1632 in men's First } \\ \text { Division and } 448 \text { in } \\ \text { women's First Division) }\end{array} & \begin{array}{l}\text { The home advantage was higher than 50\% in both } \\ \text { leagues, with significantly higher values in the male } \\ \text { league. Teams scored a higher percentage of goals } \\ \text { when playing at home, no differences were found } \\ \text { between genders. Regarding the number of goals }\end{array} \\ & \begin{array}{l}\text { scored per match, the results showed differences } \\ \text { between genders, with higher values in the men's } \\ \text { league }\end{array}\end{array}$




\section{Comparative analysis}

The researchers sought to explain players' activity and compare performances depending on: (1) players' position [31, 32]; (2) match half [23, 32]; (3) phase of the competition [30]; (4) age group [20, 26, 35]; (5) game result [17-19, 32]; and (6) home advantage [36] (Table 2).

\section{Discussion}

The purpose of this paper was to review the available literature on match analysis in rink hockey. In the following sections, we discuss the most pertinent results emerging from the studies reviewed.

\section{Descriptive analysis}

The descriptive studies reviewed in the next sections of this paper characterize the game of rink hockey by describing collective behaviours or activity profile.

\section{Collective behaviours: ball possession}

Through the reviewed studies, we concluded that most of the offensive actions were performed in short periods of time, which led to a high number of ball possessions per game (range: 55.6-105.5). Additionally, there are differences regarding ball possession between the top 4 teams of the U-17 Portuguese league and the U-17 Portuguese national team [18, 20]. The analysis of the top $4 \mathrm{U}-17$ teams of the Portuguese league revealed that, on average, each team had 105.5 ball possessions per game. This number of ball possessions is substantially higher than that in the U-17 Portuguese national team. Duque [18] observed a total of 520 ball possessions (across the 4 games analysed) corresponding to 65 ball possessions per team, while Vaz [20] estimated 55.6 ball possessions per game. The differences observed between the 2 aforementioned studies might be explained by the changes applied in the game rules in 2009 [37]. One of the modifications was the introduction of a 45-second rule, which states that after a team gains possession of the ball, they have 45 seconds - timed by a 'shot clock' - to finish the offensive process. This change seems to have made the game more dynamic owing to the reduction in the number of game interruptions. Before the World Skate (International Olympic Committee recognized organizational body for roller sports) introduced changes to the rules of the game [37], many coaches used fouling as a defensive strategy to stop the opposition's offensive build-up. Nowadays, these fouls count and can even lead to a temporary exclusion of a player from the game, leaving the team 'short-handed,' with a reduced number of active players (similar to the penalty kill in ice hockey). A longitudinal analysis could help understand the implications that the changes in the rules of the game [37] have brought to rink hockey.

Similar results were found for the Portuguese U-20 and senior teams. They performed, on average, 201 ball possessions per game, which represents an average of 100 ball possessions per team [17, 22, 26]. Similar values in different age group teams could be related to the fact that both seniors and U-20 play games of 50 minutes ( 2 halves of 25 minutes each) and also to the higher technical-tactical development of the players. This observed number of ball possessions per team is higher than the 76 ball possessions per game performed by the Portuguese national team during the U-20 European championship [21]. However, caution should be taken when analysing these results as games at the European championships had a total duration of 40 minutes (2 halves of 20 minutes each).

Concerning defensive actions, it has been previously suggested that there is an association between these types of behaviour and the end of an offensive action [27]. The reviewed studies imply that this is the same for all age groups. Ball possession is regained mainly by the successful execution of defensive actions (such as duel, interception, recovery of ball possession after a save from the goalkeeper) or owing to the laws of the game (such as ball out, faults) [17-19, 21, 22, 26, 27]. Mendo and Anguera Argilaga [27] confirmed this tendency through a study of patterns of play in high level rink hockey teams, concluding that a shot on goal or a goal scored were related to specific patterns of defensive organization and mainly related to the way the ball was regained (direct or indirect recovery of ball possession). As rink hockey is characterized by a low effectiveness of the offensive process despite the high number of ball possessions per game, the ability to recover ball possession after a shot on goal is one of the most important actions during a game. In this sense, all the players have a fundamental role in this moment of the game, not only the goalkeeper, because of the specific dynamics of this sport. However, Mendo and Anguera Argilaga [27] highlighted the importance of goalkeeper's actions. After a save from the goalkeeper, defensive patterns of ball recovery emerge from both teams.

Across all age groups, the defensive and intermediate areas of the rink (zones 1, 2, 3, and 4) (Figure 3) are the preferential areas to start offensive actions $[17-19,21,22]$. The reviewed studies indicated that in every age group (U-17, U-20, and seniors), ball possession started preferentially in defensive and interme- 
diate areas. However, some offensive sequences started in the last offensive third (zones 5 and 6) (Figure 3) [18]. In sports like football [38], regaining possession of the ball in more offensive areas is related to increased effectiveness of the offensive process. In the reviewed studies on rink hockey, this type of relationship was not investigated and should be one of the variables analysed in future research. Although there are no studies that relate ball regained possession with the effectiveness of the offensive process in rink hockey, Rosa [19] concluded that the area of the rink where ball possession started could be associated with the type of defensive organization adopted by the team in the defensive process or the strategy employed by teams and managers.

\section{Collective behaviours: type of attack}

Rink hockey is a fast game where the offensive actions tend to occur over a duration of less than 9 seconds [19, 21, 22, 26]. On average, a rink hockey team needs approximately $3-8$ seconds to complete a counterattack [19, 21, 22], while organized attacks, on average, do not extend beyond 9 seconds [20, 22, 23].

Although rink hockey is a fast game, a more organized build-up style of play is the preferred offensive method across all age groups. An analysis of the offensive organization of the U-17 Portuguese national team reveals that the time spent on organized attacks was higher $(73.7 \%$ of total playing time) compared with counter-attacks [20]. On average, the time in ball possession by the Portuguese national team was 1136 seconds (63\%) and the average time spent in sectors 5 (front of the goal) and 6 (behind the goal) was 518 seconds, while the time spent in sector 4 (intermediate zone) was 393 seconds. More recently, Vaz et al. [28] concluded that there was a predominance of offensive midfield interactions, particularly in sector 4 , and finalization in 5C (Figure 3).

Offensive or defensive recovery of the ball (e.g., tackle, shot at goal, fault, intercepted pass) is associated with the start of an organized attack [17-19, 21, 22, 26]. Tackles and opponent mistakes are the predominant actions that precede a counter-attack [1719, 21, 22, 26]. Moreover, less frequently, missed goals, recovery of ball possession, and intercepted passes are also actions that precipitate offensive sequences of a counter-attack.

With regard to situations that lead to fast attacks, the most common behaviours are shots on goal and actions of defensive recovery of ball possession [19, 21, $22,26]$. Additionally, events such as faults, ball recovery in offensive midfield, offensive mistakes, and even the scoring of goals appear to be related with this type of offensive organization [17, 18, 26].

Counter-attacks and fast attacks are frequently ended with a shot on goal [21,22], while organized attacks tend to be stopped through a fault by the opponent team or through a shot on goal by the team in possession of the ball [22]. Concerning the areas where attacks are concluded, counter-attacks and fast attacks tend to end in the central offensive area, while organized attacks frequently end in both offensive lateral corridors, and less frequently in the intermediate offensive area [21].

\section{Collective behaviours: finishing action}

In rink hockey, almost half of the offensive actions end with a shot on goal (48\%), while in floorball the total is $42 \%$ [39], and only $3 \%$ of those shots end in goal scored [17]. In futsal, a sport with some resemblances to rink hockey (i.e., same number of players and similar field dimensions), a study conducted by Vicente-Vila and Lago-Peñas [40] led to the conclusion that teams playing at home presented higher values of effectiveness (17.4\%) when compared with away teams (14.4\%). These values of effectiveness were substantially higher than those presented by Ferreira [17]. In games between senior teams, fast attack is the offensive game method that causes more shots on goal when related to the number of ball possessions (50\%), while counter-attacks produce a lower percentage of attempted shots (41\%). Fast attacks seem to be related to a higher degree of efficiency (i.e., a goal being scored, 6\%), while counter-attack and organized attack display lower efficiency values (2\%) [18]. The U-17 group present a different tendency as counter-attacks lead to more attempted shots when accounting for the number of ball possessions (39\%) and are also the most efficient game method (17\%), contrasting with organized attacks, which exhibit much lower efficiency values (5\%) [18]. These results can be explained by the tactical culture of senior players (compared with the U-17 group), preventing situations of unbalanced defensive structure. It seems pertinent that coaches consider the need to choose better finishing situations, as well as to explore the attack time allowed by the rules of the game (45 seconds timed by a 'shot clock').

Central areas near the goal are most frequently used by rink hockey players to finish offensive sequences, as is observed in other team sports like football [38] and futsal [41, 42]. The area where a team starts the offensive process influences the effectiveness of the offensive process. When the offensive process stars in the opposition defensive area, the odds of ending with 
a goal scored are higher than when the offensive process starts in the intermediate or in the defensive area [23]. The effectiveness of the offensive sequences are also associated with the central offensive zones, with nearly $87 \%$ of goals scored from there [17]. Youth (U-17) teams presented a similar tendency, with $74 \%$ of the attempted shots resulting in a goal performed in the central offensive zones. However, players tend to finish counter-attack and fast attack situations more frequently from a shot in the intermediate area [18]. This result suggests that at this age, youth players are not at an adequate technical/tactical maturity level to progress to the more advanced areas of increased offensiveness where they are more likely to score a goal. Nevertheless, coaches consider it important to know the areas of the field where the percentage of effectiveness of the offensive sequences is highest, thus developing strategies to improve their players and teams [29].

In order to characterize the offensive phase, Vaz [20] divided offensive actions into 3 types: (1) offensive actions of type I are identified as complete collective actions (with a shot at goal); (2) offensive actions of type II are identified as incomplete collective actions (without a shot at goal; e.g., loss ball, fault); (3) offensive actions of type III are identified as situations involving a set-play with the possibility of final actions (e.g., direct free hit, penalty, indirect free hit). Collecting the number of type I actions throughout the game and the potential for offensive finalization can allow an assessment of the effectiveness of a team's offensive build-up. Through the application of the offensive build-up effectiveness index and the overall finalization index, we can obtain an approximate idea of the performance and attitude of a team in relation to the task of offensive build-up, allowing the identification of success in this game phase [20].

The effectiveness of the offensive phase in the Portuguese U-17 national team reveals low values of the finalization index (percentage of team's success in solving offensive finalization problems), evaluated from the following formula: $\mathrm{FI}=$ (scored goals/number of collective actions type I and III) $\times 100(11.8 \%)$, and of the global finalization index (average ability of a team to produce finishing situations throughout the offensive phase of the game), evaluated from the following formula: GFI = sum of the brokerage indices of collective actions type I and III (13.5\%) [20]. The values of the index of efficiency for the offensive build-up (number of collective actions type I/number of collective actions type I and type II $\times 100)(64.2 \%)$ and the index of efficiency for the defensive build-up (success of a team in solving defensive problems) (55.3\%) suggest a predominance of ball possession with finaliza- tion (actions type I and III) [20]. The ability to cancel the offensive organization of the opponent teams generates a positive differential of almost $10 \%$.

\section{Activity profile}

Rink hockey players perform, on average, 1004.7 actions per game, with 3.7 seconds spent on each action. Ball transfer (i.e., passing) and tackling are the most frequent actions in the game [20]. Additionally, rolling is the most frequent skating activity, with the most prolonged mean duration (7.6 seconds) [30], and it is in the second half that players perform the highest percentages of rolling [31]. Sprinting occurs for only $4 \%$ of game time and is more frequent in the first half of a match [31, 32]. In general, $22 \%$ of the game is classified as high-intensity activity and $77 \%$ as low-intensity activity. In sports like field hockey [43] and futsal (considered a high-intensity sport) [44], a lower percentage of match time is spent in high-intensity activities ( $5 \%$ and $13.7 \%$, respectively). The higher percentages of low-intensity activities appear in the second halves of the matches [33]. Similar findings were reported by Dogramaci et al. [45] when comparing international and Australian national futsal games.

More recently, Fernández et al. [25] gathered the information on external load during 9 matches of the 2017/2018 season of Spanish league (OK Liga) through an ultra-wideband positioning system. The authors collected information from 8 players and concluded that regarding external load competition demands, the distance travelled by a rink hockey player was clearly lower than in outdoor sports [46, 47]. However, in another study, performed with the same positional system and the same sample of players, Fernández et al. [24] collected positional data to determine the most demanding passages through the distance covered in high-speed skating $\left(>18 \mathrm{~km} \cdot \mathrm{h}^{-1}\right)$ during a match, and also in training drills. The authors concluded that they could not reproduce the most demanding passages of the match in training situations.

The offensive area (central corridor) is where players perform situations of 1 vs. 1 most often, and the most frequent type of dribble is the dribble in progression (technical-tactical action in which the player attempts to overtake the opponent in order to create a finishing action) [30]. The most common shot is the forehand flick shot, and this is also the shot type that takes the most time to execute [30]. Kingman and Dyson [33] concluded that goalkeepers spent substantially longer times positioned in the centre of the goal $(68.7 \%)$, while only $18.6 \%$ of the time was spent on the left side of the goal and $12.7 \%$ on the right side. Rink 
hockey goalkeepers tend to be less effective when the shot is performed in their defensive area and to the upper zones of the goal, and more effective in the middle [23, 33]. While Kingman and Dyson [33], analysing 6 English Premier League matches, concluded that the shots placed in the top right of the goal were more successful (38.2\%), Sousa et al. [23] investigated 1713 shots on goal from the Portuguese First Division 2016/ 2017 and implied that it was in the top left of the goal that the goalkeepers were less effective (35.8\%). These results are in concordance with a study by Almeida et al. [48], who analysed 536 penalties in 2010-2015 UEFA Champions and Europa League (football).

The most frequent technique used by rink hockey goalkeepers is the 'knee on the floor' [23]. The authors compared different techniques applied by the goalkeepers and concluded that 'fleck,' 'spatula,' and 'side fall' were less efficient than the 'knee on the floor' technique.

The results concerning the activity profile of rink hockey can help coaches and practitioners to design specific training sessions reflecting the game demands. However, the knowledge provided by the reviewed studies is still insufficient, which highlights the need for more research on this type of activity.

\section{Comparative analysis}

In the reviewed comparative studies, researchers sought to explain player's activity and compared performances in accordance with player position, match half, phase of competition, age group, final result, and home advantage.

\section{Players' positions}

Rink hockey players are divided into 3 main field positions: goalkeepers, defenders/midfielders, and forwards [20]. Forwards perform significantly higher percentages of dribbling, with a significantly longer mean duration compared with other positions [31]. They also exhibit a significantly higher frequency of tackles, forehand flick shots, backhand flick shots, and slide stops right [32]. However, it was not possible to calculate correlations between playing position and the intensity or direction of movement.

The results show that the technical demands are different depending on the player's position on the field. This information is valuable for coaches and may help them to optimize training protocols and improve performance.

\section{Match half}

Throughout the game, it is possible to verify that in the first half, players perform more sprints, collect more loose balls (without being in possession), and execute slide stops left with more frequency than slide stops right. However, in the second half of matches, there is more falling, and the game is played with a lower intensity [32]. Also, goalkeepers tend to be more effective in the first halves compared with the second halves of the matches [32]. The decrement of physical performance in the second half of competition has been verified in different sports like football $[15,49]$ or rugby [50]. We postulate that the decrements in physical performance observed in the second half of a rink hockey match is due to fatigue; however, this requires further investigation. It is possible that reduced physical outputs are a result of accumulated fatigue, pacing, or situational factors such as the score line or strategical-tactical adaptation by the 2 teams. Furthermore, a considerable change in the rules of the game occurred in 2009 [37]. One of the main changes involved a technical sanction of punishment with a direct free hit each time a team accumulated 10 fouls or 5 additional team fouls. The application of this rule has resulted in more direct free hits in the second halves of the matches. Given that rink hockey goalkeepers are less effective at saving direct free hits [23], the combination of physical capacity reduction and the rule changes can contribute to the decline of effectiveness in the second halves of the matches.

It is necessary to develop more scientific knowledge about the physical demands in competition, as well as understanding how coaches can bring training exercises closer to the physical demands of the competition. Simulating game situations through small-sided games and conditioned games, which involve competition between players, may help to approximate the intensity of training to that of competition. The use of monitors (such as global positioning systems and heart rate sensors), which make it possible to quantify the external and the internal load of the players, will allow coaches and researchers to have a clearer view about what training exercises can approach the physical demands of the game and, in this way, to be able to approximate the demands of training to the demands of competition.

\section{Phase of the competition}

During competitions, it is possible to detect changes in athlete performance. Bastos [30] monitored the performance of the elite Portuguese national team during 
the 2003 World Championship, investigating mainly 1 vs. 1 situations. The author concluded that the number of goals scored was higher in the qualifying phase when compared with the final phase of the competition (quarter-final, semi-final, and final). Additionally, a low number of 1 vs. 1 situations during organized attacks were observed in the second phase of the competition. This decline may be a result of more balanced matches, with successful 1 vs. 1 situations being harder to achieve.

\section{Age groups}

In U-13, U-15, and U-17 age groups, forward players perform a higher number of passes, while among U-20 and seniors, defenders present greater OutDegree levels (identification of centrality level of a player when passing the ball) [35]. These differences can be a consequence of the utilization of the best young players as forwards in younger age groups, allowing these players to have more ball possession and be more accurate in the offensive phase. In older age groups, the game is more tactical, and defenders assume a more significant prominence at the beginning of offensive possessions and also in maintaining ball possession [36].

The number of ball possessions per game increases as the athletes go up in age group (U-17: 130; U-20: 152; seniors: 201) [26]. This may be a result of the short period of playing time in U-17 when compared with older age groups (U-17: 40 minutes; U-20: 50 minutes; seniors: 50 minutes). On the other hand, the difference between U-20 and seniors could be explained by the fact that in older age groups, the intensity of the game is higher, and players have a greater technical-tactical development. Valente-dos-Santos [26] concluded that the percentage of organized attack was higher in U-20 when compared with U-17 teams and that $28 \%$ of ball possession ended with shot on goal in both age groups. Counter-attack loses importance in older age groups, and fast attacks gain greater relevance through the age groups [27].

In the U-17 category, regained ball possessions are performed mainly through faults and defensive rebounds, while in the U-20 category, most of the ball possessions start after a tackle, defensive recovery, or a fault [27]. In most offensive actions, the defensive organization overcomes the offensive organization, i.e., the recovery of ball possession by the defensive team, most of the time, is performed after a tackle, a fault, or a shot at goal [20,26].

\section{Game result}

With regard to the final game result, winning teams perform more fast attacks and counter-attacks, while losing teams have more ball possessions in organized attack [18, 19], which can reveal specific team strategies for the winning team. When winning, teams prefer to utilize counter-attacks, exploiting offensives mistakes to create situations of offensive superiority, while losing teams have to play in continuous attack because the winning team adopt a more defensive posture. According to Ferreira [17], there are no differences between winners and losers concerning ball possession; counter-attacks differentiate winning teams from losing teams. Better defensive teams have more chance of finishing attacks in numerical superiority. Furthermore, winning teams, besides having a more significant number of counter-attacks, also execute more shots at goal. These findings are in concordance with what happens in other team sports like football, where winning teams decrease their ball possession, which suggests that they prefer to play using counter-attack or direct play (move the ball quickly to within the scoring range) [51].

Losing teams spend a higher percentage of a half shooting backhand slap shots and present a significantly higher mean duration of dribbling, while winners fall more frequently; for both, however, intensity and direction had no evident score effects [32].

\section{Home advantage}

Home advantage is a widely accepted phenomenon and has been analysed in different sports contexts [52-55]. It is important to consider and understand the effect that competing at home has on the result of sports competitions.

An analysis of the men's and women's Portuguese league provided evidence of greater home advantage in the men's league, although a significant number of goals were scored when playing at home both in men's and in women's league [55]. The difference between genders in home advantage could be explained by such factors as crowd effect and referee bias, territorial protection, and psychological aspects [56].

\section{Limitations}

Rink hockey has received little interest from the scientific community. To the best of our knowledge, this is the first systematic review of match analysis in rink hockey. Moreover, because of this lack of interest by 
researchers, much of the available literature might be published as grey literature, which makes it difficult to locate. Another limitation of this review is the fact that we only searched publications written in Portuguese and English. Perhaps if the search had been extended to other languages (e.g., Spanish, Italian, French, or German), more studies would have emerged. Moreover, extending the search to a higher number of electronic databases could have identified a higher number of publications.

Additionally, we would like to highlight the fact that this review only included 5 studies with a sample collected after the 2009 rule change [23-25, 35, 36]. The main difference is that with the introduction of the 2009 rule change [37], teams have 45 seconds to shot at goal, whereas before 2009, there was no time limit. Furthermore, when a team makes 10 fouls, they are penalized with a direct free hit to the opposition, with a direct free hit for every 5 fouls thereafter. This difference in game rules has modified the game dynamics. Nowadays, the game seems more fluid than it was before 2009. However, there is a lack of studies that would provide empirical data related to the differences caused by the rule change.

\section{Conclusions}

In the last few years, there has been an increase in the number of scientific publications on rink hockey. However, research in match analysis is scarce. Most of the studies in match analysis are academic works (theses) that have never been published in international scientific journals, which limits access to the knowledge produced in these studies to the international scientific community, as well as to rink hockey coaches.

From this review, it is possible to conclude that rink hockey is a fast game with low effectiveness, offensive actions tend to occur in periods below 9 seconds, and teams prefer organized attacks to counter-attacks or fast attacks. Rink hockey players perform, on average, 1004.7 actions per game, spending an average of 3.7 seconds on each action. Travelling with the ball and tackling are the most frequent actions.

When we consider ball possession, it is possible to conclude that most of the offensive actions are performed in short periods and lead to a higher number of ball possessions per game (range: 55.6-105.5). Furthermore, the ball is regained mainly by defensive actions and owing to the laws of the game. Defensive and intermediate areas of the field are where teams preferentially start their offensive actions, and teams prefer central areas near the goal to end these actions.
Rink hockey players' most frequent actions are ball conduction and tackling. Although rink hockey is considered a high-intensity game, most of the actions are performed at a low intensity ( $77 \%$ of the actions), and the majority of low-intensity actions are conducted during the second halves of matches. Moreover, winning teams perform more counter-attacks and fast attacks in comparison with losing teams, who undertake more organized attacks.

\section{Future research}

To obtain more knowledge about the transformations introduced to the game with the 2009 rule change, more scientific research is required, particularly using newer technologies (e.g., global positioning systems, match analysis software) and also new approaches to the study of tactical sequential events (e.g., networks, sequential patterns). Rink hockey has been growing since it was created as a team sport and the current challenge is to provide scientific knowledge that will allow its extensive development, as seen in football [15] and basketball [14].

Future studies should conduct more detailed analysis of the activity profile of players and goalkeepers, the tactical and technical demands of the game depending on situational variables (such as quality of opposition, match half, game location), the effectiveness of the offensive process, and the existence of patterns of play.

\section{Ethical approval}

The conducted research is not related to either human or animal use.

\section{Disclosure statement}

No author has any financial interest or received any financial benefit from this research.

\section{Conflict of interest}

The authors state no conflict of interest.

\section{References}

1. Areces Gayo A. Roller hockey as a team sport. Analysis and optimization of game systems through tactical indicators [in Spanish]. Doctoral thesis. A Coruña: Universidade da Coruña; 2000.

2. Garganta J. Performance analysis in sports games. Game analysis review [in Portuguese]. Rev Port Cienc Desporto. 2001;1(1):57-64; doi: 10.5628/rpcd.01.01.57.

3. Carling C, Bloomfield J, Nelsen L, Reilly T. The role of motion analysis in elite soccer: contemporary performance measurement techniques and work rate data. 
Sports Med. 2008;38(10):839-862; doi: 10.2165/000 07256-200838100-00004.

4. Oliveira NMJ. Comparative study of children with and without valgus knees practising roller hockey with different analysis systems [in Portuguese]. Master thesis. Porto: Instituto Superior de Engenharia do Porto, Departamento de Física, Universidade do Porto; 2012.

5. Rink-hockey in the world (2014). Available from: http:// rinkhockey.net/rinkhockey2014.pdf.

6. Kingman JC, Dyson RJ. The scientific literature available on roller hockey. J Hum Mov Stud. 2001;41(6): 415-433.

7. Ferraz A, Valente-Dos-Santos J, Sarmento H, DuarteMendes P, Travassos B. A review of players' characterization and game performance on male rink-hockey. Int J Environ Res Public Health. 2020;17(12):4259; doi: 10.3390/ijerph17124259.

8. Valente-dos-Santos J, Sherar L, Coelho-E-Silva MJ, Pereira JR, Vaz V, Cupido-Dos-Santos A, et al. Allometric scaling of peak oxygen uptake in male roller hockey players under 17 years old. Appl Physiol Nutr Metab. 2013;38(4):390-395; doi: 10.1139/apnm-2012-0178.

9. Coelho-E-Silva MJ, Vaz V, Simões F, Carvalho HM, Valente-Dos-Santos J, Figueiredo AJ, et al. Sport selection in under-17 male roller hockey. J Sports Sci. 2012; 30(16):1793-1802; doi: 10.1080/02640414.2012.709262.

10. Silva M-RG, Silva H-H. Comparison of body composition and nutrients' deficiencies between Portuguese rink-hockey players. Eur J Pediatr. 2017;176(1):41-50; doi: 10.1007/s00431-016-2803-x.

11. Sarmento H, Clemente FM, Araújo D, Davids K, McRobert A, Figueiredo A. What performance analysts need to know about research trends in association football (2012-2016): a systematic review. Sports Med. 2018; 48(4):799-836; doi: 10.1007/s40279-017-0836-6.

12. Agras H, Ferragut C, Abraldes JA. Match analysis in futsal: a systematic review. Int J Perform Anal Sport. 2016; 16(2):652-686; doi: 10.1080/24748668.2016.11868915.

13. Prieto J, Gómez M-Á, Sampaio J. From a static to a dynamic perspective in handball match analysis: a systematic review. Open Sports Sci J. 2015;8(1):25-34; doi: 10.2174/1875399X01508010025.

14. Courel-Ibáñez J, McRobert AP, Ortega Toro E, Cárdenas Vélez D. Collective behaviour in basketball: a systematic review. Int J Perform Anal Sport. 2017;17(1-2): 44-64; doi: 10.1080/24748668.2017.1303982.

15. Sarmento H, Anguera MT, Pereira A, Araújo D. Talent identification and development in male football: a systematic review. Sports Med. 2018;48(4):907-931; doi: 10.1007/s40279-017-0851-7.

16. Sarmento H, Marcelino R, Anguera MT, Campaniço J, Matos N, Leitão JC. Match analysis in football: a systematic review. J Sports Sci. 2014;32(20):1831-1843; doi: 10.1080/02640414.2014.898852.

17. Ferreira L. Internal structure of the roller hockey game: exploratory study of ball possession at senior men's level [in Portuguese]. Bachelor thesis. Coimbra: Faculdade de Ciências do Desporto e Educação Física, Universidade de Coimbra; 2003.

18. Duque G. Internal structure of the roller hockey game: exploratory study of ball possession at youth men's level [in Portuguese]. Bachelor thesis. Coimbra: Faculdade de Ciências do Desporto e Educação Física, Universidade de Coimbra; 2004.

19. Rosa C. Internal structure of the roller hockey game: exploratory study of ball possession in youth national team [in Portuguese]. Bachelor thesis. Coimbra: Faculdade de Ciências do Desporto e Educação Física, Universidade de Coimbra; 2006.

20. Vaz V. Sports specialization in young male hockey players. A study of young athletes, the selection process, and performance structure [in Portuguese]. Doctoral thesis. Coimbra: Faculdade de Ciências do Desporto e Educação Física, Universidade de Coimbra; 2011.

21. Ferreira J. Analysis of the game and sports performance in roller hockey [in Portuguese]. Bachelor thesis. Coimbra: Faculdade de Ciências do Desporto e Educação Física, Universidade de Coimbra; 2005.

22. Clérigo LFC. Internal structure of the roller hockey game: exploratory study of ball possession in the youth Portuguese national team [in Portuguese]. Bachelor thesis. Coimbra: Faculdade de Ciências do Desporto e Educação Física, Universidade de Coimbra; 2006.

23. Sousa T, Sarmento H, Marques A, Field A, Vaz V. The influence of opponents' offensive play on the performance of professional rink hockey goalkeepers. Int J Perform Anal Sport. 2020;20(1):53-63; doi: 10.1080/ 24748668.2019.1704499.

24. Fernández D, Novelles A, Tarragó R, Reche X. Comparing the most demanding passages of official matches and training drills in elite roller hockey. Apunt Educ Fis Deporte. 2020;2(140):77-80; doi: 10.5672/apunts. 2014-0983.es.(2020/2).140.11.

25. Fernández D, Varo F, Carmona G, Reche X. Quantification of external load of elite rink hockey players in official matches. J Sports Med Phys Fitness. 2020;60(12): 1520-1525; doi: 10.23736/S0022-4707.20.11097-1.

26. Valente-dos-Santos J. Analysis of the game and sports performance in roller hockey: concept, methods, and applications at the youth, junior, and senior levels [in Portuguese]. Bachelor thesis. Coimbra: Faculdade de Ciências do Desporto e Educação Física, Universidade de Coimbra; 2006.

27. Mendo AH, Anguera Argilaga MT. Behavioral structure in sociomotor sports: roller-hockey. Qual Quant. 2002;36(4):347-378; doi: 10.1023/A:1020905411739.

28. Vaz V, Dias G, Gama J, Couceiro M, Valente-dos-Santos J, Rafael J, et al. Network of interpersonal interactions in roller hockey. Int J Sports Sci. 2016;6(1A):1-7; doi: 10.5923/s.sports.201601.01.

29. Sousa T. Exploratory study and internal consistency of a system of observation and analysis of roller hockey 
teams and athletes [in Portuguese]. Master thesis. Coimbra: Faculdade de Ciências do Desporto e Educação Física, Universidade de Coimbra; 2014.

30. Bastos D. Analysis of $1 \times 1$ in the offensive process in roller hockey: study carried out with the Portuguese national team in the 2003 World Cup [in Portuguese]. Bachelor thesis. Coimbra: Faculdade de Ciências do Desporto e Educação Física, Universidade de Coimbra; 2005.

31. Kingman JC, Dyson RJ. Analysis of roller hockey match play. J Hum Mov Stud. 1997;32(6):235-251.

32. Kingman JC, Dyson RJ. Player position, match half and score effects on the time and motion characteristics of roller hockey match play. J Hum Mov Stud. 1997;33(1): 15-30.

33. Kingman J, Dyson R. Video analysis of shot distribution and goalkeeper movement during roller hockey match play. Biomechanics Symposia. 19 International Symposium on Biomechanics in Sports (2001) - Conference Proceedings Archive. 2001;70-73.

34. Ferreira D. The influence of the positional constraint of the goal in the offensive decision-making process in roller hockey [in Portuguese]. Master thesis. Funchal: Departamento de Educação Física e Desporto, Universidade da Madeira; 2008.

35. Oliveira P, Clemente FM, Martins FML. Who is the prominent tactical position in rink-hockey? A network approach based on centrality metrics. J Phys Educ Sport. 2015;15(4):657-662; doi: 10.7752/jpes.2015.04100.

36. Arboix-Alió J, Buscà B, Trabal G, Aguilera-Castells J, Sánchez-López MJ. Comparison of home advantage in men's and women's Portuguese roller hockey league. Cuad Psicol Deporte. 2020;20(1):181-189.

37. World Skate - Rink Hockey Technical Commission. Rules of the game \& technical regulation. World Skate; 2018.

38. Sarmento H, Figueiredo A, Lago-Peñas C, Milanovic Z, Barbosa A, Tadeu P, et al. Influence of tactical and situational variables on offensive sequences during elite football matches. J Strength Cond Res. 2018;32(8): 2331-2339; doi: 10.1519/JSC.0000000000002147.

39. Gómez M-Á, Prieto M, Pérez J, Sampaio J. Ball possession effectiveness in men's elite floorball according to quality of opposition and game period. J Hum Kinet. 2013;38(1):227-237; doi: 10.2478/hukin-2013-0062.

40. Vicente-Vila P, Lago-Peñas C. The goalkeeper influence on ball possession effectiveness in futsal. J Hum Kinet. 2016;51:217-224; doi: 10.1515/hukin-2015-0185.

41. Santana WC, Laudari BA, Istchuk LL, Arruda F. Analysis of the goals in high-level female futsal matches [in Portuguese]. Rev Bras Cienc Mov. 2013;21(4):157-165.

42. Sarmento H, Bradley P, Anguera MT, Polido T, Resende R, Campaniço J. Quantifying the offensive sequences that result in goals in elite futsal matches. J Sports Sci. 2016; 34(7):621-629; doi: 10.1080/02640414.2015.1066024.

43. Spencer M, Lawrence S, Rechichi C, Bishop D, Dawson B, Goodman C. Time-motion analysis of elite field hockey, with special reference to repeated-sprint activity. J Sports Sci. 2004;22(9):843-850; doi: 10.1080/026 40410410001716715.

44. Barbero-Alvarez JC, Soto VM, Barbero-Alvarez V, Granda-Vera J. Match analysis and heart rate of futsal players during competition. J Sports Sci. 2008;26(1): 63-73; doi: 10.1080/02640410701287289.

45. Dogramaci SN, Watsford ML, Murphy AJ. Time-motion analysis of international and national level futsal. J Strength Cond Res. 2011;25(3):646-651; doi: 10.1519/ JSC.0b013e3181c6a02e.

46. Clemente FM, Santos Couceiro M, Martins FML, Ognyanova Ivanova M, Mendes R. Activity profiles of soccer players during the 2010 World Cup. J Hum Kinet. 2013;38:201-211; doi: 10.2478/hukin-2013-0060.

47. King T, Jenkins D, Gabbett T. A time-motion analysis of professional rugby league match-play. J Sports Sci. 2009;27(3):213-219; doi: 10.1080/02640410802538168.

48. Almeida CH, Volossovitch A, Duarte R. Penalty kick outcomes in UEFA club competitions (2010-2015): the roles of situational, individual and performance factors. Int J Perform Anal Sport. 2016;16(2):508-522; doi: 10.1080/24748668.2016.11868905.

49. Pratas J, Volossovitch A, Ferreira AP. The effect of situational variables on teams' performance in offensive sequences ending in a shot on goal. A case study. Open Sports Sci J. 2012;5(1):193-199; doi: 10.2174/1875399 X01205010193.

50. Duthie GM, Thornton HR, Delaney JA, McMahon JT, Benton DT. Relationship between physical performance testing results and peak running intensity during professional rugby league match play. J Strength Cond Res. 2017;34(12):3506-3513; doi: 10.1519/JSC.00000000 00002273.

51. Lago-Peñas C, Dellal A. Ball possession strategies in elite soccer according to the evolution of the matchscore: the influence of situational variables. J Hum Kinet. 2010;25(1):93-100; doi: 10.2478/v10078-0100036-z.

52. Sánchez PA, García-Calvo T, Leo FM, Pollard R, Gómez MA. An analysis of home advantage in the top two Spanish professional football leagues. Percept Mot Skills. 2009;108(3):789-797; doi: 10.2466/PMS.108.3.789-797.

53. Koning RH. Home advantage in speed skating: evidence from individual data. J Sports Sci. 2005;23(4):417-427; doi: 10.1080/02640410400021625.

54. Gómez MA, Pollard R, Luis-Pascual J-C. Comparison of the home advantage in nine different professional team sports in Spain. Percept Mot Skills. 2011;113(1):150156; doi: 10.2466/05.PMS.113.4.150-156.

55. Arboix-Alió J, Aguilera-Castells J. Analysis of the home advantage in roller hockey [in Spanish]. J Sport Health Res. 2019;11(3):263-272.

56. Prieto J, Gómez M-Á, Pollard R. Home advantage in men's and women's Spanish first and second division water polo leagues. J Hum Kinet. 2013;37(1):137-143; doi: 10.2478/hukin-2013-0034. 